\title{
Spatial Models of Consumer Choice for Retail Outlets: Theory and Practice in Physics of Marketing
}

\author{
M. J. Alhabeeb ${ }^{1}$ \\ ${ }^{1}$ University of Massachusetts, USA \\ Correspondence: M. J. Alhabeeb, University of Massachusetts, USA. E-mail: mja@resecon.umass.edu
}

Received: October 19, 2018 Accepted: November 20, $2018 \quad$ Online Published: January 11, 2019

doi:10.5539/ijms.v11n1p1 URL: https://doi.org/10.5539/ijms.v11n1p1

\begin{abstract}
A theoretical review and an assessment of applications of the spatial models of consumer choice for retail outlets are presented here. As they are also called gravitational models in marketing, they remain relevant in today's retail world despite the explosion of e-commerce. The major objective here is to emphasize the theoretical significance of these models, analyze their practicality in the market, and refer to their validity today. The focus would be on the original Reilly's model of the early thirties of the last century, and the two most significant improvements over it, Converse's model of the late forties, and Huff's model of the early sixties. After a detailed exposition of these models and their applications, a critical analysis is introduced to address the retail site selection, radius of the trading area, limitations of the models, and some criticism.
\end{abstract}

Keywords: spatial models, gravitational models, Reilly's law, Huff's model, Converse's model

\section{Introduction}

In the last decade or so, e-commerce and consumer's online retail purchases have been astronomically increasing. In 2017, e-commerce has exploded to about half of the whole retail growth, although it constituted only $13 \%$ of total retail transactions. While consumer spending in 2017 reached $\$ 453.5$ billion on the web for retail purchases, which was an increase of $16 \%$ over the previous year, total retail sales reached to over five trillion dollars in the same year, representing a 4.4\% increase over the 2016 figure (digitalcommerce $36 . c o m$ ).

This significant growth in e-commerce has not yet indicated an all-out march towards replacing the traditional way of commerce and trade. Traditional retail outlets, large and small, continue to grow, and the so-called brick-and-mortar stores continue to be built and expand their commercial activities. On the other hand, consumers too, do not seem to be ready to give up what they have long gotten used to of old-fashioned methods of shopping. According to a 2017 Consumer View Report by the National Retail Federation (NRF), four out of five American consumers still prefer to shop at brick-and-mortar stores (Inc.com, October $2^{\text {nd }}, 2017$ ). Moreover, most retail companies tend to establish an on-line sale site only to enhance their store retail activities, rather than to replace them. This evidence supports the notion that consumer choice of where to shop is still in the heart of their top considerations as they seek the retail outlet that would yield the highest utility for them, economically and otherwise.

There have been a few major approaches to analyze consumer choice of retail outlet. Frisk and Choi (2013) list some of these theoretical frameworks: Analog models would depend on projecting sales using existing data and growth patterns of trade; Regression models utilize econometrical techniques and forecasting methods to estimate sales subject to major variables such as population size, consumer income, number of households and alike. Central Place theory attributes consumer travel for shopping to the extent of availability of a wide variety of consumer goods and services at certain retail outlets. Unlike these models, spatial models utilize the physical gravitational theory and rely on variables such as size of population, size of market, location of retail outlets, and distance between the competing outlets in order to delineate certain retail trading area, and explain consumer rationale to choose an area of shopping over other alternatives. In that sense too, these models can explain the rationale of trading company to choose their outlet locations.

The pioneering work in the area of spatial modeling in marketing has been credited to Professor William J. Reilly of Texas University, who in his studies of 1929, 1931, and 1953, came up with what we now know as the law of retail gravitation. It was inspired by Newton's law of gravity in physics. It was a study of retail activities 
and an analysis of consumer shopping patterns using a mathematical approach to explain the extra travel of rural consumers to large towns to satisfy most of their shopping needs. It has been considered the antithesis of most of the traditional retailing models, which confine consumers' choice to their own geographical areas. Reilly's work of 1931 and his revision of 1953 succeeded to attract many researchers into following his footstep and generating a wave of model modifications, revisions, and applications (Christaller, 1935; Converse, 1949; Applebaum, 1961; Huff, 1963; Jones \& Mock, 1984; Fotheringham \& O’Kelly, 1989; Rust \& Danthu, 1995).

The objective of this paper is to revisit the spatial models of consumer choice and marketing, emphasize their significance, analyze their applications, and refer to their relevance today. The focus would be on the original Reilly's model of the early thirties of the last century, and the two most significant improvements over it, Converse's model of the late forties, and Huff's model of the early sixties. After a detailed exposition of these models, our critical analysis will address the retail site selection, radius of the trading area, limitations, and criticism.

\section{Reilly's Gravitational Model}

Isaac Newton (1642-1727) came up with his theory of universal gravitation in 1686 . His law states that "every particle attracts every other particle in the universe with a force directly proportional to the product of their masses, and inversally proportional to the square of the distance between the centers of the masses". The force of attraction between the masses acts along a straight line intersecting their centers. It is mathematically expressed by:

$$
\mathrm{F}=\mathrm{G}\left[\frac{m_{1} m_{2}}{\mathrm{r}^{2}}\right]
$$

Where $\mathrm{F}$ is the gravitational force, $\mathrm{m}_{1}$ and $\mathrm{m}_{2}$, are the masses, $\mathrm{r}$ is the distance between the centers of the masses, and $\mathrm{G}$ is a gravitational constant.

In 1929, Professor Reilly started his endeavor to model retail trade areas in a study entitled "Methods for the Study of Retail Relationship" in which he utilized consumer survey, census data, and city retail data to explain those methods. It served as the basis for his 1931 Law of Retail Gravitation in which he utilized the aforementioned Newton's law of universal gravity." According to Reilly's adaptation, two business site locations or two cities, as represented by the size of their population, would be analogous to Newton's particles. The central idea, therefore, was to focus on determining the trade area boundaries around commercial centers that would be impacted by their masses such that there would be a law of gravitation modeled after Newton's. This law states that "two cities attract trade from an intermediate town in the vicinity of the breaking point, approximately in direct proportion to the populations of the two cities, and in inverse proportion to the square of the distances from these two cities to the intermediate town". The mathematical expression for that would be:

$$
\left[\frac{\mathrm{Bx}}{B y}\right]=\left[\frac{P x}{P y}\right]\left[\frac{D y}{D x}\right]^{2}
$$

Where:

$\mathrm{Bx}$ : is the proportion of the trade from the intermediate town attracted by city $\mathrm{x}$.

By: is the proportion of the trade from the intermediate town attracted by city $y$.

Px: is the population of city $\mathrm{x}$.

Py: is the population of city $y$.

Dx: is the distance from intermediate town to city $\mathrm{x}$.

Dy: is the distance from intermediate town to city y.

\section{Converse's Revision}

Based on Reilly's notion of the breaking point, Professor P.D. Converse of the University of Illinois was able to formulate an expanded breaking point model. In his 1949 study entitled "New Laws of Retail Gravitation", he derived a new equation to delineate the trading area boundaries between city $\mathrm{x}$ and city $\mathrm{y}$. Reilly assumed that the trade areas around the cities would be equal so that the midpoint in the linear distance between them would be what he called the breaking point. It is the point at which customers would be indifferent about going to either location for shopping. However, if the two cities have different sizes of population, the breaking point would be determined by Converse's equation: 


$$
\mathrm{d}_{\mathrm{x}}=\frac{\mathrm{D}_{\mathrm{xy}}}{1+\sqrt{\frac{\mathrm{P}_{\mathrm{y}}}{\mathrm{P}_{\mathrm{x}}}}}
$$

where:

$\mathrm{d}_{\mathrm{x}}$ : is the distance of the break point from city $\mathrm{x}$.

$\mathrm{D}_{\mathrm{xy}}$ : is the linear distance between the two cities $\mathrm{x}$ and $\mathrm{y}$.

$\mathrm{P}_{\mathrm{x}}$ : is the population size of $\mathrm{x}$.

$\mathrm{P}_{\mathrm{y}}$ : is the population size of $\mathrm{y}$.

As illustrated in Figure 1, if the distance between city $\mathrm{x}$ and city y is 60 miles and they have the same size of population, say 200,000, the trade areas around them would be equal so that the midpoint in the linear distance between them would be Reilly's breaking point. But if their populations are now different at 140,000 for city x and 350,000 for city $y$, and the distance between the two cities stays the same as 60 miles, the breaking point (dx) would then be calculated by:

$$
\begin{gathered}
\mathrm{d}_{\mathrm{x}}=\frac{60}{1+\sqrt{\frac{350,000}{140,000}}} \\
=\frac{60}{1+\sqrt{2.5}}=\frac{60}{1+1.58}=23.2
\end{gathered}
$$

The direct conclusion of this law, as it is related to the selection of business sites, is that it would give an entrepreneur a general understanding that customers are impacted by how far they have to travel to buy what they want, and how many customers are around any specific location. Of course, the assumption was that the distance between the two locations was flat and plain. That was without accounting for any barrier or difficulty related to the geography of the area, or the traffic problems or any other complication.

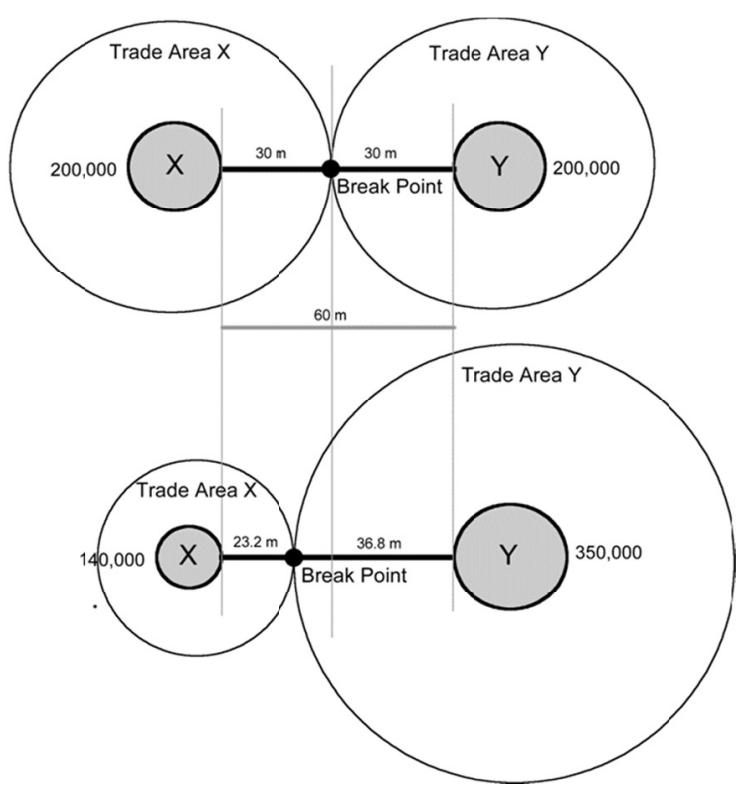

Figure 1. Reilly's breaking points between cities of equal and unequal populations 
Converse ran an empirical test on three Illinois towns: Farmer City, Champaign-Urbana, and Bloomington-Normal. As illustrated below, the distance between Farmer City and Champaign-Urbana is 25 miles, and between Farmer City and Bloomington Normal is 27 miles. Population of Champaign-Urbana is 37,366 and of Bloomington-Normal is 39,851 (1940's figures).

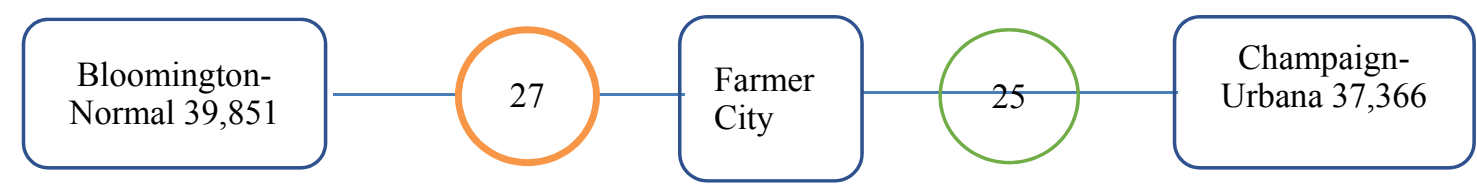

Figure 2. Converse's relative trade between three Illinois towns

He calculated the relative trade for a farmer City consumer between Bloomington-Normal (b) and Champaign-Urbana (c) by:

$$
\begin{aligned}
{\left[\frac{\mathrm{B} b}{B c}\right]=\left[\frac{P b}{P c}\right]\left[\frac{D c}{D b}\right]^{2} } \\
=\left[\frac{P b}{P c}\right]\left[\frac{25}{27}\right]^{2}=.915
\end{aligned}
$$

He concluded that Bloomington-Normal would get 0.915 times as much trade as what Champaign-Urbana gets, so the relative percentage of trade for each can be calculated as:

$$
\begin{aligned}
& \mathrm{B}_{\mathrm{b}}+\mathrm{B}_{\mathrm{c}}=1 \\
& \mathrm{~B}_{\mathrm{b}}=1-\mathrm{B}_{\mathrm{c}} \\
& \begin{aligned}
& \mathrm{B}_{\mathrm{b}} / \mathrm{B}_{\mathrm{c}}=1 / \mathrm{B}_{\mathrm{c}}-\mathrm{B}_{\mathrm{c}} / \mathrm{Bc} \\
&=1 / \mathrm{Bc}-1=0.915 \\
&=1 / \mathrm{Bc}=1.915 \\
& \mathrm{Bc}=1 / 1.195=52.2
\end{aligned}
\end{aligned}
$$

So, Champaign-Urbana gets $52.2 \%$ of the trade while the rest of $47.8 \%$ goes as Bloomington-Normal's share.

When surveying consumers in Farmer City in 1942, he found that Champaign-Urbana attracted $55 \%$ and Bloomington-Normal attracted $45 \%$. Obtaining such close figures was an impressive empirical confirmation of Reilly's model.

Converse further raised the question about the extent to which a town would retain or lose its trade. Using a consumer survey in more than a 100 town and using the original formula but designating a home town (h), he was able to solve for the distance $\mathrm{D}_{\mathrm{h}}$, which he called the "inertia factor" and calculated its value as around 4 . The formula, therefore, was modified to:

$$
\left[\frac{\mathrm{B} x}{B h}\right]=\left[\frac{P x}{P h}\right]\left[\frac{4}{D x}\right]^{2}
$$

Where:

$\mathrm{B}_{\mathrm{x}}$ : proportion of trade going to an outside town (x)

$\mathrm{B}_{\mathrm{h}}$ : proportion of trade retained by hometown (h)

$\mathrm{P}_{\mathrm{x}}$ : population of the outside town ( $\mathrm{x}$ )

$\mathrm{P}_{\mathrm{h}}$ : population of the hometown (h)

$\mathrm{D}_{\mathrm{x}}$ : Distance to the outside town (x)

$\mathrm{D}_{\mathrm{h}}$ : Distance to the hometown (h)

4: The inertia factor as calculated by survey.

This formula was tested empirically to figure out the trade split between larger and smaller towns. The test on Benton (population 7,372) which is 7 miles from West Frankfort (population 12,383) required knowing how trade is divided between the two cities, which can be uncovered by a survey. The survey was conducted and revealed a relative percentage of $87 \%$ to Benton and $13 \%$ to West Frankfort. The reconstructed formula became: 


$$
\left[\frac{13}{87}\right]=\left[\frac{12,384}{7,372}\right]\left[\frac{X}{7}\right]^{2}
$$

Solving for $\mathrm{X}$ revealed a value of 2.1, which suggests that Benton had a better chance to retain its home trade, as compared to an area average of 3.3 retaining rate.

Based on his extensive empirical testing, Converse was able to rewrite Reilly's law into what he called a "New Law of Retail Gravitation", which states:

"A trading center and a town in or near its trade area divide the trade of the town approximately in direct proportion to the population of the two towns, and inversely to the squares of the distance factors, using 4 as the distance factor of the hometown" (Converse, 1949, p. 382).

Converse's empirical work confirmed that the inertia factor can be adjusted to the multiples of 4 to accommodate the number of towns to which a small home town would lose its trade to. Therefore, the factor could be 8 for losing to two large towns, and could be 12 for losing to three towns, and 16 to four towns and so on. His new formula was adjusted to account for the possibility of the outside town being much larger than the hometown. This is a case he faced in his work regarding Chicago and St. Louis as compared to other towns scattered around them which are significantly smaller. His empirical work revealed a negative relationship between the size of the outside town as expressed by population size and the accuracy of the prediction. He noticed that the accuracy of the results would remain reliable up to a population size 20 times the size of hometown, but beyond that, such as for sizes 50 times and more than the size of hometown, the reliability of the results would significantly drop.

As for Chicago and St. Louis vs. any small town, he adjusted the formula this way:

$$
\left[\frac{\mathrm{B} x}{B h}\right]=\left[\frac{P x}{P h}\right]\left[\frac{1.5}{D x}\right]^{2}
$$

And for a small town vs. a larger metropolitan center, he suggested raising the power of the formula from squared to cubic, and likewise to adjust the boundary formula to the cubic root.

$$
\begin{gathered}
{\left[\frac{\mathrm{B} x}{B h}\right]=\left[\frac{P x}{P h}\right]\left[\frac{4}{D x}\right]^{3}} \\
d=\frac{D_{x}}{1+3 \sqrt{\frac{P x}{P}}}
\end{gathered}
$$

\section{Huff's Revision}

D. L. Huff $(1963 ; 1964)$ focused on the fact that consumers usually have several alternatives of retail outlets to shop from, which makes the dynamics of their decision making probabilistic rather than deterministic, as it is the case with Reilly's and Converse's. Therefore, his central idea is not only how probable a consumer chooses this outlet versus other outlets, but also covered consumer utility of shopping at a certain outlet as a proportion of the collective utilities out of shopping at the rest of outlets. He argues that the whole matter of consumer choice here is not plain, but rather complex, continuous and stochastic. He refers to specific limitations of Reilly's and Convers's models such as:

- The models' inability to make gradual estimates above and below the breaking point between the two towns.

- The models' inconsistency between the over-lapping boundaries and the basic objective of the formula of delineating the retail trading area.

- The models' assertion on the inertia factor being a constant while it varies with different types of shopping trips.

Therefore, according to Huff's new model, consumer choice of the retail outlet for his shopping would depend on the size of outlet and how long it would take the consumer to reach that outlet. After all, it is a probability against the other probabilities related to the rest of shopping outlets in a specific area. This probability is measured by:

$$
P i j=\frac{S_{j} / T_{i j}^{\gamma}}{\sum_{j=1}^{n}\left(S_{j} / T_{i j}^{\gamma}\right)}
$$


Where:

$P i j$ : is the probability for consumer $\mathrm{i}$ to shop at outlet $\mathrm{j}$

$S_{j}$ : square footage of the retail outlet

$T_{i j}^{\gamma}$ : time which consumer i would take to get to outlet $\mathrm{j}$

$\gamma$ : empirical parameter to reflect the effect of travel time on different shopping trips

Once the probability is calculated, it would be easier to obtain the expected number of consumers to shop at that outlet (Eij) by multiplying the calculated probability (Pij) by the total number of consumers in that area (Ci):

$$
\mathrm{Eij}=\mathrm{Pij}(\mathrm{Ci})
$$

Huff was able to confirm his model empirically as well as he was able to expand it to calculate the sales of a specific area by multiplying per capita consumer expenditures in that area by the population size in that trade area (Huff, 1966; Huff \& Batsell, 1977; Huff \& Rust, 1984). As quoted by Friske and Choi (2013), a study by Anderson, Volker, and Phillips (2010) argued that "Huff's model of trade area gravitation is widely regarded as the industry standard for determining the probability of a retail location to attract customers". Friske and Choi (2013) also listed the studies that modified and expanded on Huff's model since its publishing in mid-sixties. They include Lakshmanan and Hansen (1965) who calculated aggregate sales in shopping centers and assessed consumer utility trade-off between travel distance and outlet size; Bucklin (1967) and Gonzalez-Benito (2005) who considered the store image as a new determinant variable in retail attraction; Nakanishi and Cooper (1974, 1988) who replaced Huff's retail store size by a researcher-determined set of attributes in what is called a multiplicative interaction model. Others such as Jain and Mahajan (1979); Achabal, Gorr, and Mahajan (1982); Ghosh and Craig (1992); Drezner (1994); and Gonzalez-Benito, Munoz-Gallego, and Kopalle (2005) considered consumer heterogeneity, market heterogeneity, and longitudinal effects on the dynamics of Huff's model.

In their study in the Hispano-Lusitanian frontier area, C.C. Yrigoyen and Jose V. Otero of the University of Madrid, Spain presented a slightly different notation of Huff's model:

$$
\begin{gathered}
P i j=\frac{U i j}{\sum_{k=1}^{j} U i k} \\
P i j=\frac{S_{j}^{\alpha} D_{i j}^{\beta}}{\sum S_{k}^{\alpha} D_{i k}^{\beta}}
\end{gathered}
$$

Where:

$P i j$ : is the probability for consumer $\mathrm{i}$ to shop at outlet $\mathrm{j}$

Uij: is the utility of consumer $\mathrm{i}$ derived from shopping at outlet $\mathrm{j}$

$S_{j}$ : square footage of the retail outlet

Dij: the distance that consumer $\mathrm{i}$ travels to get to outlet $\mathrm{j}$

$\alpha, \beta$ : sensibility parameters, where according to Reilly, they equal 1 and -2 respectively.

The researchers confirmed Luce's (1959) notion on the relative utility that was adopted by Huff. It states that the probability of a consumer shopping at a particular outlet is equal to the ratio of the utility derived out of that outlet to the sum of utilities derived from all the rest of alternative outlets.

Using the formula above, the researchers were able to calculate the probabilities for a consumer living in the municipality of Moura to shop at outlets in three towns: Beja, Vora, and Badajoz. The following table shows the calculations:

Table 1. Probabilities of consumer choice of retail outlets among three Spanish towns

\begin{tabular}{llllll}
\hline Outlet & $\begin{array}{l}\text { Distance(D) } \\
(\mathrm{km})\end{array}$ & $\begin{array}{l}\text { Size(S) } \\
(\mathrm{sq})\end{array}$ & $\mathrm{D}^{-2}$ & $\mathrm{SD}^{-2}$ & Probability $(\mathrm{P})$ \\
\hline Badajoz & 133 & 55.319 & 5.653 & 3.127 & 0.62 \\
Evora & 89 & 8.725 & 1.263 & 1.102 & 0.22 \\
Beja & 58 & 2.628 & 0.3 & 0.78 & 0.16 \\
T0tal & & & & 5.009 & 1 \\
\hline
\end{tabular}


The empirical work revealed that the probability of a consumer to choose the retail outlets in Badajoz is $62 \%$, and in Evora 22\%, and in Beja 16\%. This is to say that a consumer is likely to travel to Badajoz for shopping almost four times more than his travel to Beja and three times more than his travel to Evora.

\section{Critical Analysis}

\subsection{Radius of the Trading Area}

As we have seen above, the trading area of business can be defined by the circle surrounding the business. It refers to the geographic area from which a business would get its major customers. The size of this area, or let's say, the radius of that circle, can be influenced by the type of business, its size, the uniqueness of its product or service, the variety of its offerings, accessibility, complementary or substituting businesses, and barriers. It is important not to be confused about the impact of the variety of business offerings, specialty of business, and uniqueness of its product, which may sound contradictory. While the wider variety of products and services the business can offer, the more customers it can draw, it is also true that a unique product or service would draw customers from a greater distance. If one movie theater is available in an area, customers would come to it from a wider circle. The same would occur if there is only one shop specialized in repair of sewing machines, then you would find people traveling a great distance to get this service, although we are talking here about a specific segment of consumers. Ease and comfort of accessibility to a location would increase the radius of the trading area. Accessibility here could be the availability and ease of transportation, communication, parking, as well as better customer services. This is why we see most of the shopping malls are located by major highways. The more complementary and the less substitutive businesses surrounding the location, the more customers can be drawn to a certain location. Take for example a shopping plaza that offers a department store, general and convenient stores, trendy clothes store, shoe store, beauty salon, hair cut salon, kids' playground and games, auto repair garages, in addition to some restaurants and cafes. Such a plaza would satisfy most of the consumers' needs in any given trip to the point it might be preferred over any other alternatives regardless of the distance and ease of travel. Also, the more customer's barriers, the smaller the trading area for a business. Barriers here could be economic such as higher taxes, and more expensive transportation, and fewer and more expensive parking. It could also be cultural barriers such as the exclusiveness of an area or location to a special group, and could also be related to a higher or lower crime rate in specific area.

\subsection{Site Selection}

As for the use of these spatial models in business site selection, one of the basic criteria, in addition to attracting more customers, is the consideration of a possible expansion and renovation in the future. If a business does well, it would most likely respond to the high demand and customer satisfaction by expanding the facility and adding more of the variety to the products and services. This would be a possibility to think about and, therefore, the considered site must be flexible enough to accommodate any future plan for expansion and renovation in the future.

In the times of developing these models, shopping places were likely scattered across the land, and in most towns and cities, the downtown area was traditionally a place for a variety of small businesses clustered among government and professional offices. The biggest advantage for such confined locations was the high traffic of customers versus many disadvantages such as the high rent, difficult traffic, lack of adequate parking, and safety issues. Later on, shopping plazas and malls started to grow across the land rapidly. The most striking features of shopping plazas and malls is the clustering of a wide variety of businesses that function under one roof and benefit from the continuous stream of customers.

\subsection{Applications and Limitations}

Gravitational and spatial models, whether deterministic or probabilistic, gained over the years many theoretical and empirical supports, and found their place in many applications in different fields. In addition to the primary application in consumer choice of retail shopping and marketing for consumer goods and services, boundaries of trade, and business site selection, they also found their way to many other applications beyond the primary realm. Constantin (2004) argued that gravitational and spatial models were applied in a wide variety of studies such as those devoted to migration, commodity flow, traffic flow, and residence-workplace trips. Like any other theoretical concepts, these models have their own limitations, especially when they are put into practice. Some of these limitations and shortcomings were addressed by the subsequent modifications and revisions throughout the past nine decades since Reilly's pioneering study. Some limitations were recognized by the original studies and other limitations were pointed out to by other critical studies. At the time when Reilly subjected his model to empirical testing he meant to predict consumer choices in rural areas as they had to travel to shopping outlet away from their street corner little general store. Also, he predicted their travel pattern as they demanded some 
ubiquitous goods. In later years and in further revisions, the models became valid for all consumers and all consumer goods and services.

As Huff presented his significant improvement to both Reilly's and Converse's models, he recognized certain limitations as well as he argued for specific contributions of his own revision. Huff argued that he considered the trading area as a demand surface with potential consumers of specific products of a particular distribution center that could be a single firm or an agglomeration of firms. Also the demand surface can consist of a series of zones whose commercial activities are of a probabilistic nature where the potential customers are the sum of the expected number of consumers from each of the zones. In addition to that, demand zones of competing firms overlap so a spatial competitive equilibrium position can be reached. (Huff, 1949). Needless to say that Huff's contributions came as a remedy to what he envisioned as the major limitations of the original Reilly model and Converse's revision, as they are mentioned above.

\subsection{Criticism}

Despite the wide support to the spatial models in academia and industry, there has been some criticism, especially on the notion that these models have lost their luster and validity with the rapid transformation of market to the electronic commerce and the popularity of on-line trade which made it possible for retail companies to fundamentally alter the dynamics of place and time to reach their customers (Sheth and Sisodia 1999). This argument does not seem to be valid, especially if we recall the evidence presented in the opening of this paper that confirms the fact that physical stores and retail establishments are here to stay and not going to fade away, at least in the forceable future. One major justification for people to shop at physical establishments like malls and plazas can very well be of a hedonic nature. Consumers derive pleasure from the process of consumption as a whole as opposed to only the using up element of consumption. This is to say people often enjoy going to shop even if they do not really need to buy anything or whether or not they end up buying a specific product. We all know that most people go to restaurants and cafés not really because they do not have food at home but they go for the pleasure of being there whether alone or with a company. Same reason can be argued for going to a movie theater or the mall, which adds more good reasons for the existence of these places and makes traveling to them a matter of rational decisions that may need studies such as the spatial models.

\section{References}

Anderson, S. J., Volker, J. X., \& Phillips, M. D. (2010). Converse's breaking-point model revised. Journal of Management and Marketing Research, 1-10.

Applebaum, W., \& Cohen, S. B. (1961). The dynamics of store trading areas and market equilibrium. Annals of the Association of the American Geographers, 51, 73-101. https://doi.org/10.1111/j.1467-8306.1961.tb00369.x

Converse, P. D. (1949). New laws of retail gravitation. Journal of Marketing, 14(Jan.), 379-384. https://doi.org/10.2307/1248191

Constantin, D. L. (2004). The use of gravity models for spatial interaction analysis. Economy Informatics, 1(4), $116-118$.

Drews, P. L. (1970). An Assessment of Reilly's Model of Consumer Behavior, 16-28.

Fotheringham, A. S., \& O’Kelly, M. E. (1989). Spatial Interaction Models: Formulations and Applications. Kluwer Academic Publishers.

Friske, W., \& Choi, S. (2013). Another look at retail gravitation theory: History, analysis, and future consideration. ABD Journal, 5(1), 1-17.

Huff, D. L. (1963). A probabilistic analysis of consumer spatial behavior. In W. S. Decker (Ed.), Emerging concepts in marketing (pp. 443-461). Chicago: American Marketing Association.

Huff, D. L. (1964). Defining and estimating a trade area. Journal of Marketing, 28, 34-38. https://doi.org/10.2307/1249154

Huff, D. L. (1966). A programmed solution for approximating an optimal retail location. Land Economics, 42, 293-303. https://doi.org/10.2307/3145346

Huff, D. L., \& Batsell, R. R. (1977). Delimiting the areal extent of a market area. Journal of Marketing Research, 14(Nov.), 58-65. https://doi.org/10.2307/3151205

Huff, D. L., \& Rust, R. T. (1984). Measuring the congruence of market areas. Journal of Marketing, 48(Winter), 68-74. https://doi.org/10.2307/1251312. https://doi.org/10.1177/002224298404800107 
Jones, K. G., \& Mock, D. R. (1984). Evaluating Retail Trading Performances: Store Location and Store Assessment Research. New York: Wiley.

Jones, M. A., Reynolds, K. E., \& Arnold, M. J. (2006). Hedonic and utilitarian shopping value: Investigating differential effects on retail outcomes. Journal of Business Research, 59(9), 974-981. https://doi.org/10.1016/j.jbusres.2006.03.006

Luce, R. (1959). Individual choice behavior. New York: Wiley

Nakanishi, M., \& Cooper, L. G. (1974). Parameter estimate for multiplicative interactive choice model: Least squares approach. Journal of Marketing Research, 11, 303-311. https://doi.org/10.2307/3151146

Pan, B., Hembrooke, H., Joachims, T., Lorigo, L., Gay, G., \& Granka, L. (2007). In Google we trust: Users' decisions on rank, position, and relevance. Journal of Computer-Mediated Communication, 12(3), 801-823. https://doi.org/10.1111/j.1083-6101.2007.00351.x

Reilly, W. J. (1929). Methods for the study of retail relationships. Austin, TX: Bureau of Business Research.

Reilly, W. J. (1931). The Law of Retail Gravitation. NY: W.J. Reilly, Inc.

Reilly, W. J. (1953). The law of retail gravitation (2nd ed.). New York, NY: Pilsbury Publishers.

Rust, R. T., \& Donthu, N. (1995). Capturing geographically localized misspecification error in retail store choice models. Journal of Marketing Research, Feb., 103-110. https://doi.org/10.2307/3152115

Shaw, E. H., \& Jones, D. G. B. (2005). A history of schools of marketing thought. Marketing Theory, 5(3), 239281. https://doi.org/10.1177/1470593105054898

Sheth, J. N., Gardner, D. M., \& Garrett, D. E. (1988). Marketing Theory: Evolution and Evaluation. New York, NY: Wiley.

Sheth, J. N., \& Sisodia, R. J. (1999). Revisiting marketing's lawlike generalizations. Journal of the Academy of Marketing Science, 27(1), 71-87. https://doi.org/10.1177/0092070399271006

Yrigoyen, C. C., \& Otero, J. V. (1998). Spatial interaction models applied to the design of retail trade areas. The 38th Congress of the European Regional Science Association: August-September, Vienna, Austria.

\section{Copyrights}

Copyright for this article is retained by the author, with first publication rights granted to the journal.

This is an open-access article distributed under the terms and conditions of the Creative Commons Attribution license (http://creativecommons.org/licenses/by/4.0/). 